\title{
Fertility capability classification and GIS mapping of soils in Agbarho town, Delta State, Nigeria
}

\author{
Ufuoma Efe, Akpovwovwo \\ Department of Geography and Regional Planning, Delta State University, Abraka, Nigeria.
}

Received 10 April, 2013; Accepted 15 May, 2014

\begin{abstract}
The rapid increase in population growth in Nigeria has led to increased pressure on available land for agricultural uses, resulting in land degradation and subsequent soil infertility. This situation has in turn resulted in the desperate need of farmers to improve their yields and profits. The fertilizers utilized for this purpose are usually not compatible with the soil needs which are known to vary over space. The need therefore arises for the classification of soils based on their nutrient deficiencies. This study attempts a Fertility Capability Classification of the soils of Agbarho town, an area located within the Niger Delta region of Nigeria. A mapping of this classification was carried out with the use of Geographic Information System. A total of 60 soil samples from a depth of $0-20 \mathrm{~cm}$ were collected and analyzed for macronutrients, organic matter, $\mathrm{pH}$, cat ion exchangeable capacity and particle size composition. It was revealed that four out of the nine villages within the study area had major fertility constraints characterizing them as predominantly sandy soils possessing low ability of retaining nutrients such as potassium, calcium and magnesium. It is therefore recommended that a more detailed classification and mapping of the entire Niger Delta area be carried out.
\end{abstract}

Key words: Agriculture, soil infertility, fertility capability classification, fertility mapping, fertilizers, Niger Delta region.

\section{INTRODUCTION}

Soil is a vital resource to the sustenance of human and animal existence on earth. As a renewable resource, however, the period of renewal is long spanning hundreds of years, often loosing the topmost layer at a rate that far exceeds the capacity of its natural process of regeneration. Within the last decade, inventories of the soils' productive capacity indicate severe degradation on more than $10 \%$ of the earth's vegetative land as a result of soil erosion, atmospheric pollution, excessive tillage, overgrazing, land clearing and desertification (Wood et al., 2000).

The relevance of agriculture to the sustenance of life cannot be overemphasized. This is especially so for a country like Nigeria with its large population and consequent pressure on the use of land for agriculture. Aside from the challenge of the availability of the land for agriculture, the issue of soil fertility is also a problem. This is especially so, in areas where the parent material is inherently deficient in basic nutrients. This is the case in the Niger Delta region of Nigeria, which is underlain basically by sedimentary rocks. In this case, the soils are mainly fertilized by the overlying decomposing leaves from trees. As a result of large scale deforestation, due mainly to urbanization, resulting in a major proportion of

*Corresponding author. Email: ufo_vosa@yahoo.com, Tel: +2348028364196.

Author(s) agree that this article remain permanently open access under the terms of the Creative Commons Attribution License 4.0 International License 
the soil being laid bare, the above situation is no longer the case. Consequent on the above, any improvement on the fertility of the soil, at this juncture is therefore largely dependent on inputs such as fertilizers, farming systems or soil management methods adopted.

In confirming this situation further, Agboola and Akinnfesi (1991) noted that the soils of the humid tropics are known to generally possess a low fertility status as a result of high mean temperatures and high rainfall intensities. It was also noted that the soils of the humid tropics are known to suffer multiple deficiencies of nutrients and by implication having low productivity. The major constraints of tropical soils by implication are chemical and not physical.

Against this backdrop, a need therefore arises for the evaluation and testing of specific soils from a general to a more localized setting. This is with the purpose of effectively determining the appropriate fertilizer to be utilized in any of such areas, as this will aid in improving the soil fertility of the area in question. The goal of soil testing or evaluation has to do with helping farmers to increase production and profits dependability through the proper use of fertilizers and soil amendments. The proper use and right proportion of soil amendments and fertilizers is greatly influenced by the nature of the soil in terms of the nutrient content of the soil. Enwezor (1985) however noted that it was futile to expect to be able to predict productivity accurately from soil available nutrient content alone.

In recent times, a variety of attempts have been made to further counter the problem of soil infertility. One major attempt in this direction is the advent of the Fertility Capability Classification (FCC). The Fertility Capability Classification is the first technical soil classification that categorizes soils according to their fertility constraints in a qualitative manner. This classification was developed in response to a perceived under utilization of soil survey information. It was discovered that the upper few centimeters of the soil are excluded from soil taxonomic consideration. In actual fact, properties in the top soil have been more significant to growth than subsoil properties. The FCC aids in the identification of the fertility status of the soils through the discovery of its fertility constraints (chemical and physical). This is with the aim of proffering appropriate soil management techniques which are compatible with the soil in question. Several studies have used FCC to group soils in smaller regions as the basis for further technology transfer and research (Avilan 1979). It has however been noted that in all these studies, not all the needs of the users were satisfied by the FCC resulting in slight modifications being made. This is understandably so since specific needs vary from user to user and location to location. The main aim of the FCC is however to group soils that are homogenous enough in properties that soil management decisions are the same in kind within groups and different between groups. The ultimate test of the FCC appears to be in an evaluation of the use of the system in the delivery of soil management information to the user. The FCC has great potentials for producing results which provide a less sophisticated comprehension of soil terminology and information relevant to the area. This is extremely necessary as this is expected to be useful to the local farmers.

It is against this background therefore, that this study was carried out on Fertility Capability Classification and mapping of soils in Agbarho town, Niger Delta region of Nigeria. This is with the aim of determining the extent of applicability of the classification to the environment in question and also to further determine the relevance and importance of the various criteria involved in the classification.

\section{Study area}

Agbarho town is located between longitudes $5^{\circ} 50^{\prime}$ and $5^{\circ} 59^{\prime} \mathrm{E}$ and latitudes $5^{\circ} 30^{\prime}$ and $5^{\circ} 35^{\prime} \mathrm{N}$. It has an area of about $700 \mathrm{sq} \mathrm{Km}$. The town comprises basically of the following villages namely Orhokpokpo, Oguname, Uvwiama/Uvwiamuge, Orherhe, Ikweghwu, Ughwrughelli, Ekwerhe and Ekrerahwe. The area enjoys the Tropical Equatorial climate with an average annual temperature of $30^{\circ} \mathrm{C}$ and $3130 \mathrm{~mm}$ of rainfall, while relative humidity is $80 \%-90 \%$ (Efe, 2007). The area is underlain by three stratigraphic units starting with the unconsolidated coastal plain sands (Benin) formation at the top, followed by an intervening unit of sandstone and shale called Agbada formation and bottom unit shale known as the Akata formation, representing continental, paralic and marine depositional environments respectively (Short and Stauble, 1967). Sedimentary rock formations form both the surficial and subsurface geology of the area (Odemerho, 2007). The relief of the area is generally a sloping, gently undulating plain. The vegetation is characterized by the Lowland Tropical Rainforest. This forest is characterized by distinguishable crown layers with emergent upper, middle and lower storey's giving the forest an irregular structure. The forest is endowed with trees such as Triplochiton scleroxylon, Milicia excelsa etc. The soils consist of well - drained sandy loam over coarse sandy clay loam subsoil. Agriculture dominates the economic life of the people of the study area. The bush fallow, rotational bush fallow and the compound farming, which can all be categorized as traditional farming practices are all practiced within the area. The main food crops grown include cassava, yam, maize and plantain. The major cash crops are oil palm and rubber (FEPA, 2001).

\section{MATERIALS AND METHODS}

Data for the purpose of this study were obtained basically through soil survey and laboratory analysis. The results of the laboratory 
Table 1. Mean values of chemical and physical properties of the soils of Agbarho town.

\begin{tabular}{|c|c|c|c|c|c|c|c|c|}
\hline \multirow{2}{*}{ Soil property } & \multicolumn{8}{|c|}{ Location } \\
\hline & Orhokpokpor & Uvwiamuge & Ekrerahwe & Orherhe & Ughwrughelli & Ikweghwu & Ekwerhe & Oguname \\
\hline Sodium (cmol/kg) & 0.29 & 1.15 & 0.18 & 0.29 & 0.38 & 0.24 & 0.25 & 0.23 \\
\hline Potassium (cmol/kg) & 0.14 & 0.13 & 0.17 & 0.20 & 0.19 & 0.19 & 0.18 & 0.17 \\
\hline Calcium (cmol/kg) & 2.82 & 2.81 & 2.98 & 2.49 & 2.95 & 2.78 & 2.91 & 2.87 \\
\hline Magnesium $(\mathrm{cmol} / \mathrm{kg})$ & 0.48 & 0.52 & 0.44 & 0.54 & 0.49 & 1.14 & 0.52 & 0.56 \\
\hline Av. $P(m g / k g)$ & 1.74 & 2.27 & 2.56 & 5.11 & 5.86 & 5.25 & 3.22 & 3.94 \\
\hline Organic Carbon (\%) & 3.25 & 0.96 & 0.85 & 3.91 & 0.56 & 2.70 & 0.94 & 2.08 \\
\hline Organic Matter (\%) & 5.60 & 2.21 & 1.65 & 4.68 & 0.97 & 4.64 & 1.62 & 3.58 \\
\hline Nitrogen (\%) & 0.33 & 0.10 & 0.21 & 0.27 & 0.06 & 0.27 & 0.10 & 0.21 \\
\hline $\mathrm{pH}$ & 2.92 & 4.26 & 3.87 & 2.57 & 3.69 & 3.85 & 4.00 & 3.88 \\
\hline CEC (cmol/kg) & 3.70 & 3.80 & 3.83 & 4.08 & 4.80 & 3.73 & 4.90 & 3.61 \\
\hline Sand (\%) & 87.7 & 77.8 & 75.1 & 87.1 & 87.5 & 88.9 & 86.4 & 80.4 \\
\hline Silt (\%) & 8.5 & 37.1 & 21.5 & 9.53 & 5.92 & 5.3 & 8.3 & 13.6 \\
\hline Clay (\%) & 5.0 & 5.3 & 3.33 & 3.3 & 4.2 & 5.8 & 5.3 & 4.8 \\
\hline
\end{tabular}

Source: Author's field work (2005).

analysis can be seen in Table 1.

\section{Soil sampling}

Soil samples were obtained from the farmers' fields in each of the villages making up the town. The soil samples were taken at predetermined depths of $0-10 \mathrm{~cm}$ and $10-20 \mathrm{~cm}$. The approach of sampling from predetermined depths was adopted in order to ensure comparability between samples collected from different sample quadrats (Aweto, 1978). In all, 30 farms were sampled throughout the town. A quadrat of $15 \mathrm{~m}$ by $15 \mathrm{~m}$ (representative of each farm) was delineated within each farm from which the soil samplings were carried out. Replicate soil samples were collected from five points within each farmland and mixed to form a composite sample, representative of each farmland. The purpose of this procedure is to minimize the influence of any local nonuniformity of the soil (Tisdale et al., 1985). Thirty soil samples each were taken respectively from depths of $0-10 \mathrm{~cm}$ and $10-20 \mathrm{~cm}$, resulting in a total of 60 samples in all. The samples were collected in polythene bags, labeled and air dried in preparation for the laboratory analysis.

\section{Laboratory analysis}

The soil samples were subsequently analyzed in the laboratory, for particle size composition using the hydrometer method (Bouyoucos, 1951). The exchangeable acidity was determined through the titration method (Mclean, 1965). The Cation Exchangeable Capacity was determined by the addition of the exchangeable bases and the exchangeable acidity.

The soil $\mathrm{pH}$ was determined in 1:1 soil: water solution using the $\mathrm{pH}$ meter. The organic matter content was determined by the Walkley - Black combustion method (Walkley and Black, 1934). The soil samples were leached using $1 \mathrm{~m}$ neutral ammonium acetate, and the extracts were used for determining exchangeable calcium, potassium and sodium through flame photometry, while exchangeable magnesium was determined by atomic absorption spectrophotometer. The available phospohorus was determined using the Olsen (1954) method.

\section{RESULTS AND DISCUSSION}

The soils of the study area were classified based on the Fertility Capability Classification. A mapping based on this classification was subsequently carried out with the aid of the Geographic Information System using the Idrisi GIS software. This was done to demonstrate the possibility of classification as well as visualizing the results on a map. The FCC, according to Sanchez et al. (1982), consists of categorical levels. They include three basic criteria and levels for classification which include: Type (top soil texture), Substrata (subsoil texture) and Modifiers. The class designations therefore, for each of these three levels are combined to form an FCC unit. Where more than one criterion is listed for each modifier, only one is meant to be met. The criterion listed first is usually the most desirable one and ought to be used, if data is available. Subsequent criteria are presented for use where data is limited. The modifiers are designated in the lower case letters. Not all the modifiers however were utilized in this study. It was observed that some of the criteria had the possibility of being inferred from any of the others. Aside from this, some of the other modifiers were discovered to be inapplicable to the study area. The "l" modifier was not used as it applied to only clay soil types. This was rendered inapplicable to the extremely sandy soils of the study area. The slope modifier was also deemed not necessary because the study area is generally low lying since it is located in the Niger Delta where much of the land is rather low lying and close to the sea level as can be seen in the section on the description of the study area. The vertisol modifier was found to be inapplicable to the study area as well, since the soils of the area had been discovered through the soil analysis, to be sandy and not clayey as this modifier assumes. The (') gravel and (d) dry modifiers were also 


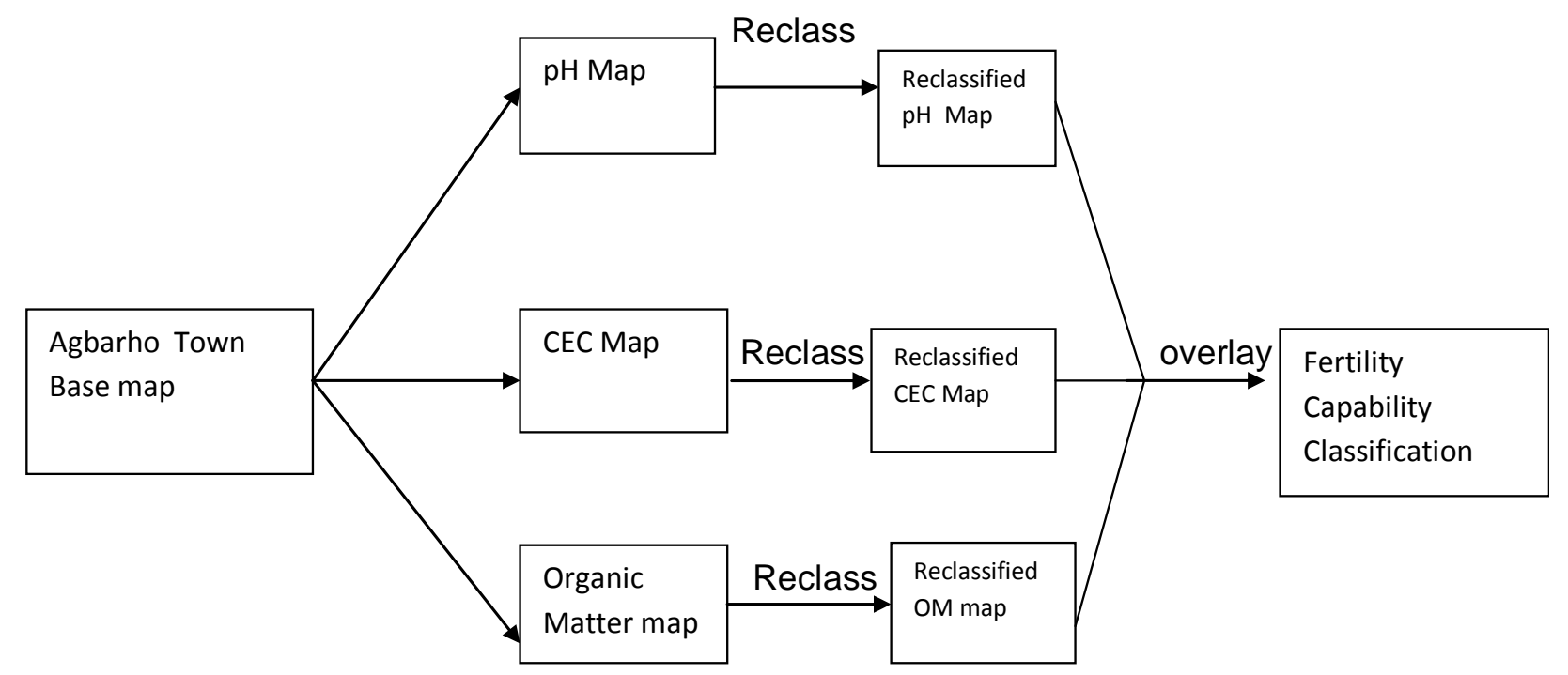

Figure 1. Cartographic model of the operations and creation of the fertility capability classification mapping of the study area.

found to be irrelevant to the study area due to the sandy and muddy nature of the soil as a result of its location in the Niger Delta and hence very high ground water level. Some other modifiers were inferred from other modifiers. The basic reaction modifier, for instance, was inferred from the $\mathrm{pH}$ modifier with the criterion of having a $\mathrm{pH}$ of $>$ 7.3.

In addition to all these other modifiers, the modifiers on $\mathrm{pH}, \mathrm{CEC}$ and Potassium were also considered. The criteria for the aforementioned modifiers included the following: $\mathrm{pH}$ modifier / (h) modifier $=\mathrm{pH}$ in 1: $1 \mathrm{H}_{2} 0$ between 5.0 and 6.0, (e) modifier = (low cation exchange capacity) applies only to the top layer or surface $20 \mathrm{~cm}$ whichever is shallower: CEC $<4$ meq $/ 100 \mathrm{~g}$ soil and $(\mathrm{k})$ (low $\mathrm{k}$ reserves) $:<0.20 \mathrm{meq} / 100 \mathrm{~g}$. This was done in conjunction with the categorization of the Type level based on the top soil. The study area was therefore mapped basically on the basis of the aforementioned criteria.

The mapping was carried out with aid of the GIS software (Idrisi GIS). This further facilitated an efficient fertility capability classification of the soils of the study area. The cartographic model of the analysis resulting in the fertility mapping can be seen in Figure 1. The cartographic model gives a step by step breakdown of the operations carried out in the process of the mapping. Maps were generated for the $\mathrm{pH}$, Potassium and CEC modifiers. This was done through the process of reclassification based on the criteria contained in the modifiers. The overlay operation was subsequently carried out on all the maps resulting therefore in the production of the final map.

The resultant map indicated the various capability classifications of all the villages within the study area. The map revealed that Uvwiama, Uvwiamuge,
Orhokpokopo and Oguname possessed major fertility constraints as seen in Figure 2. These villages were classified as Sehk. This classification implies that the aforementioned villages were characterized by the following: $S=$ Sandy topsoils, $e=$ low ability to retain nutrients against leaching of nutrient elements mainly Potassium, Calcium and Magnesium, $\mathrm{h}=$ low to medium acidity and $\mathrm{k}=$ low ability to supply potassium.

Based on the foregoing, it is being recommended that heavy applications of these nutrients and of Nitrogen fertilizers be split to avoid potential danger of over liming. These areas therefore require liming for Aluminiumsensitive crops such as cotton and alfalfa, and good latex flow in rubber. It should be noted at this point that rubber is a major cash crop of the study area and as such the relevance of this information cannot be overemphasized. Manganese toxicity may occur on some of these soils. Availability of potassium should be monitored and the use of potassium fertilizers required frequently. It should be noted that potential k-mg-ca imbalances are likely to occur. The above description and classification of the soils suggest an explanation for the observation of the planting of cassava on all the farms surveyed in the area. Cassava possesses a number of merits which could be the reason for its wide acceptability amongst the majority of local farmers within the study area and indeed the Niger Delta region of Nigeria. Apart from cassava being a staple crop for the average Nigerian, it has been found to possess the potential of adapting to marginal conditions and degraded soils. It has the advantage of possessing the ability of not being easily affected by pests and diseases. It also does not require any specialized cultivation techniques and requires no input from the harvested crop for the next season's planting material except for its stem cuttings. 


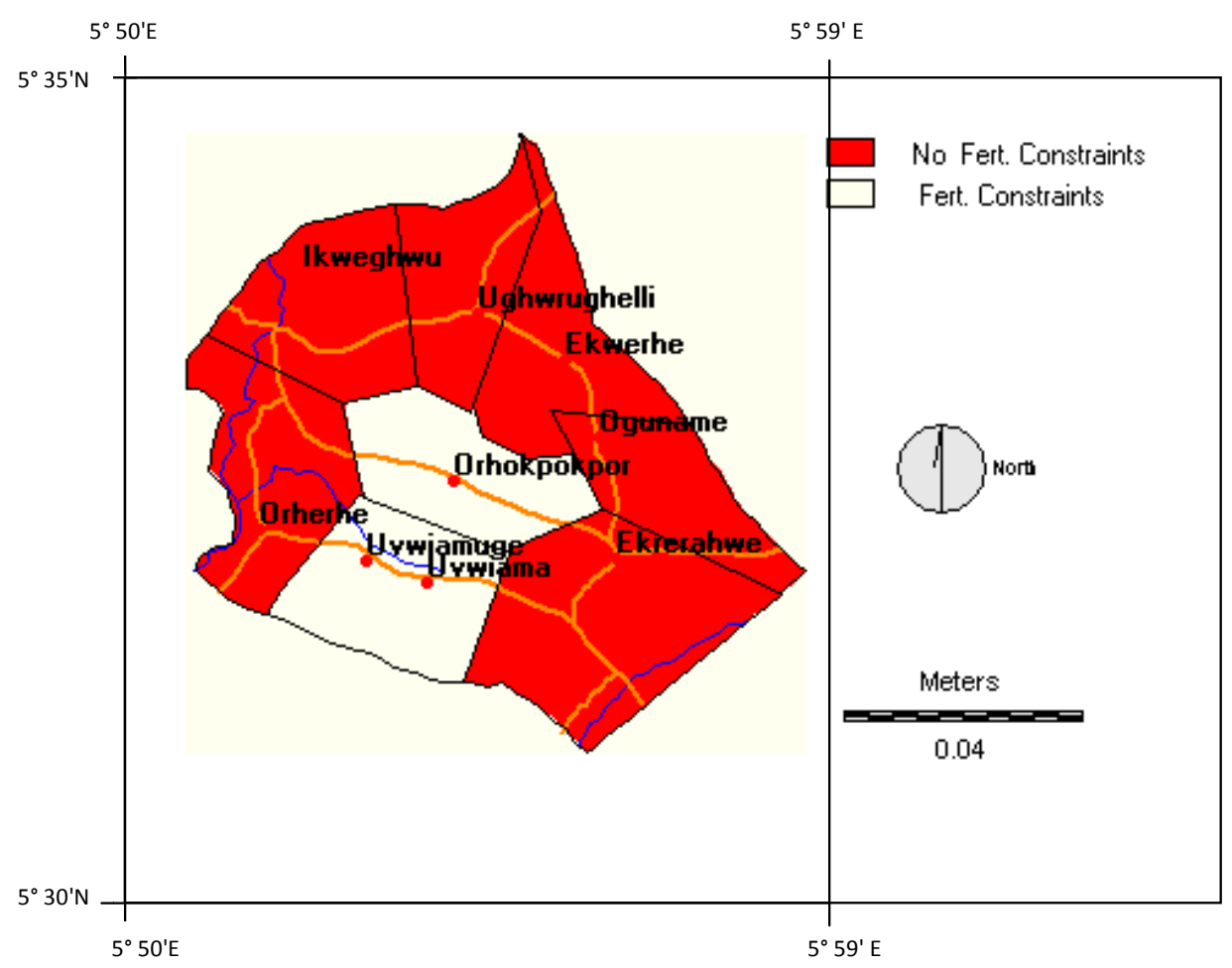

Figure 2. Fertility Capability Classification of Agbarho Town.

\section{Conclusion}

With the increasing population and decreasing availability of land for the practice of agriculture, the survival of the earth has become critical. The countries which are more likely to be affected, are the developing countries and by implication the local populace. Critical issues require radical steps. One of which, in this case, is the applicability of the Fertility Capability Classification. Several classifications have been carried out in the past, however not many have been able to effectively connect with the indigenous smallholder farmer. This classification demonstrates the possibility of the FCC of being carried out in a localized small area as against larger areas such as whole countries and continents. It has also demonstrated the ability of determining the specifics as it pertains to the nutrient deficiencies of the soils in question. The results arrived at, is expected to pave a way forward in the formulation of fertilizers containing the deficient nutrients in the right proportions. This is as against what is presently the case where fertilizers are applied to the soils without first of all determining the needs and deficiencies of the soil. In this information driven age, it is expected that computer based resources and tools are utilized for the purpose of arriving at more accurate results within a shorter time frame, as has been demonstrated with the use of GIS in this study. The GIS served as a veritable tool in effectively carrying out this classification with the major advantage of being able to visualize the nutrient deficiencies of the soil in a spatial dimension. It is indeed pertinent that studies of this type be improved upon and carried out in other localized areas. This study is of great importance and necessity, if the focus of the general populace is to be changed from oil exploration to agriculture for the purpose of sustenance and sustainability of the people.

\section{REFERENCES}

Agboola AA, Akinnfesi FK (1991). Soil fertility management for the humid tropics of Africa". Proceedings of the 2nd African Soil Science conference, Cairo, Egypt. Soil Water Manag. sustainable productivity. pp 107-122.

Avilan L (1979). In PA Sanchez et al. the fertility capability soil classification system. Interpretation, applicability and modification. Geoderma 27:283-309.

Aweto AD (1978). Secondary succession and soil regeneration in a part of SW. Nigeria. Unpublished, Ph.D. Thesis UI. Ibadan.

Bouyoucos GJ (1951). A recalibration of the hydrometer as a new method for making mechanical analysis of soils. Agron. J. pp. 434. http://dx.doi.org/10.2134/agronj1951.00021962004300090005x

Efe SI (2007). Climate of delta state. In F. O Odemerho, O.D. Awaritefe, Atubi, A.O, Ugbomeh, B. A, Efe SI (Eds) Delta State in Maps. Abraka, Department of Geography and Regional Planning, Delta state University.

Enwezor WO (1985). In: Soil fertility, soil tilth and post clearing land degradation in the humid tropics. Proceedings of international society of soil science (commissions iv and vi). Organized by The Soil Society of Nigeria. pp. 175-183.

Federal Environmental Protection Agency (FEPA) (2001). Delta State environmental Action Plan -Fina) Report (1992) Prepared for FEPA 
and Delta Slate Environmental Protection Agency by Chemical Resources Ltd. pp. 11-22.

Mclean EQ (1965). Aluminum in methods of soil analysis. Part 2. CA Black. pp. 986-994.

Odemerho FO (2007). The geology of Delta State. In F. O Odemerho, O.D. Awaritefe, Atubi, A.O, Ugbomeh BA, Efe S,I (Eds) Delta State in Maps. Department of Geography and Regional Planning, Delta State University, Abraka.

Olsen SR, Cole CV, Watanabe FS, Dean LA (1954). Estimation of available phosphorus in soils by extracts with sodium bicarbonate. USDA. Cir. P. 939.

Sanchez PA, Conto W, Buol SW (1982). The fertility capability soil classification system. interpretation, applicability and modification. Geoderma 27:283-309. http://dx.doi.org/10.1016/00167061(82)90019-2

Short KC, Stauble AJ (1967). Outline geology of Niger Delta. American Association of Petroleum Geologists Bulletin. 51(5):761-779.

Tisdale SL, Nelson WL, Beaton JD, Haulin JL (1985). Soil fertility and fertilizers. Macmillan publishing company. 5th edition. New York.
Walkley A, Black IA (1934). An estimation of the digital method for determining soil organic matter and proposed modification of the chronic acid titration method. Soil Sd. 37:29 - 38 . http://dx.doi.org/10.1097/00010694-193401000-00003

Wood S, Sabastian Scherr S (2000). Pilot analysis of global ecosystems. World Resources Institute. Washington, USA. 